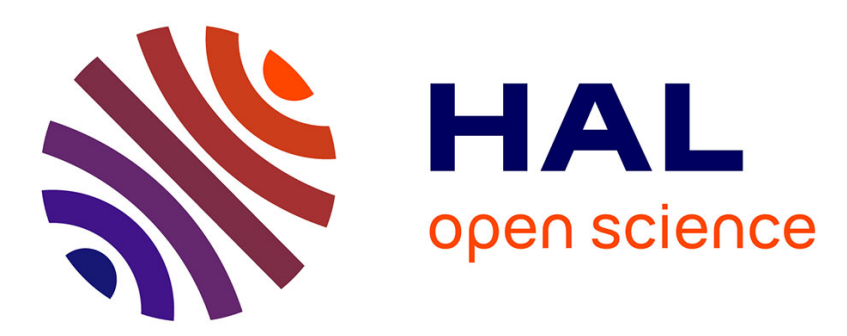

\title{
Review article: Second language acquisition welcomes the heritage language learner: opportunities of a new field
}

\author{
Silvina Montrul
}

\section{To cite this version:}

Silvina Montrul. Review article: Second language acquisition welcomes the heritage language learner: opportunities of a new field. Second Language Research, 2008, 24 (4), pp.487-506. $10.1177 / 0267658308095738$. hal-00570753

\section{HAL Id: hal-00570753}

\section{https://hal.science/hal-00570753}

Submitted on 1 Mar 2011

HAL is a multi-disciplinary open access archive for the deposit and dissemination of scientific research documents, whether they are published or not. The documents may come from teaching and research institutions in France or abroad, or from public or private research centers.
L'archive ouverte pluridisciplinaire HAL, est destinée au dépôt et à la diffusion de documents scientifiques de niveau recherche, publiés ou non, émanant des établissements d'enseignement et de recherche français ou étrangers, des laboratoires publics ou privés. 


\section{Review article Second language acquisition welcomes the heritage language learner: opportunities of a new field}

Silvina Montrul University of Illinois at Urbana-Champaign

Received October 2007; revised January 2008; accepted January 2008

Keywords: second language acquisition, heritage speakers, bilingualism, L1 loss, incomplete acquisition, language maintenance, language identity

With increasing recent changes in immigration and demographic patterns, the face of the traditional second language (L2) classroom in Spanish and the less commonly taught languages has changed dramatically in the Western World. In addition to serving typical L2 learners, these classes have recently had to accommodate an increasing number of heritage language learners. But just who are these heritage language learners? What linguistic knowledge do they bring to the classroom? And how do they differ from typical L2 learners? In this review article, I evaluate three recent books that address these questions and introduce issues relevant to the emerging field of heritage language acquisition. I argue that the heritage speaker population is very relevant for second language acquisition research because it allows us to address fundamental theoretical debates in our field from a different perspective, including debates on the role of age, input and environment, language transfer, linguistic mechanisms and the type of linguistic knowledge acquired before and after a critical period. I conclude by identifying promising avenues for research with heritage speakers and learners.

Address for correspondence: Silvina Montrul, Department of Linguistics and Department of Spanish, Italian and Portuguese, University of Illinois at Urbana-Champaign, 4080 Foreign Languages Building, MC-176, 707 South Mathews Avenue, Urbana, IL 61801, USA; email: montrul@uiuc.edu 
Brinton, D., Kagan, O. and Bauckus, S., editors, 2008: Heritage language education: a new field emerging. New York: Routledge. ISBN 978-08058-4803-8 (hardback). US\$125.

Kondo-Brown, K., editor, 2006: Heritage language development: focus on East Asian immigrants. Studies in Bilingualism, volume 32. Amsterdam: John Benjamins. $x+282$ pp. ISBN 978-90-272-4143-6 (hardback). €115, US\$155.

Valdés, G., Fishman, J., Chávez,R. and Pérez, W. 2006: Developing minority language resources: the case of Spanish in California. Clevedon: Multilingual Matters. xxi + 344 pp. ISBN 978-1-85359-898-2 (hardback). £59.95. ISBN 978-1-85359-987-5 (paperback). £24.95.

\section{Introduction}

In recent years, the face of traditional foreign language classes in the USA, Canada, Australia and Western Europe has been changing dramatically, most noticeably in the teaching of Spanish, Russian, East Asian languages (Korean, Chinese, Japanese) and the less commonly taught languages (Hindi, Turkish, Arabic, among others). Until recently, these classes were designed for, and typically populated by, learners with no previous background in the target language. Today, however, many of these classes have been opening their doors to children of immigrants. Many of these individuals have acquired these languages as a first language (L1) to some degree - either monolingually or simultaneously with the majority language - but, for a variety of reasons, their heritage language became their secondary/second language. Naturally, having typical second language (L2) learners and heritage language learners with different linguistic profiles and experiences in the same classrooms poses serious challenges to both L2 teachers and learners alike. At present, many language practitioners feel justifiably disoriented when it comes to addressing the linguistic and cultural needs of these two types of learners.

Understanding the profiles and pedagogical needs of heritage language learners is what the emerging field of Heritage Language Acquisition and education is about. Pressing research questions currently driving this field include:

- Who are heritage language speakers?

- What linguistic knowledge do they bring from childhood? 
- How can we help these learners develop, maintain and expand knowledge of the heritage language so they can use the language in a variety of formal and informal settings?

- And, perhaps most urgently, what and how should these learners be taught in the classroom?

In this article, I take a look at three recent books on minority language speakers that directly address these questions. In addition, I consider the question of how and why the heritage speaker and the heritage language learner are theoretically so relevant to the now well-established field of $\mathrm{L} 2$ acquisition.

\section{The books}

The three books share several features. They all discuss at length the linguistic and cultural variables that characterize heritage language speakers and learners, providing a good sense of the heterogeneity of this population. They all highlight how national language policies and issues of language identity impinge on the linguistic fate of this population. In Valdés et al. (2006), Joshua Fishman (p. 1) defines heritage languages as the 'colonial, indigenous, and immigrant languages other than English of the United States'. Heritage languages are languages associated with the ethno-cultural heritage of particular minority populations, which for many historical and political reasons have been devalued. Minority-language-speaking children become bilingual at a young age because they have to become members of, and interact with, mainstream society. And even when the linguistic community for the heritage language has a sizable population, as with Spanish in the USA, this in itself does not guarantee a positive role for the heritage language in the lives of these individuals.

Existing definitions of heritage speakers vary widely. Some are too broad, including children of expatriate Americans, for example, growing up speaking Japanese in Japan, or even internationally adopted children whose adoptive parents do not speak the language of their child's country of origin. On the other hand, other definitions are too narrow, referring to individuals with high proficiency in the heritage language. Valdés (2000) defines heritage speakers in terms of what they can do linguistically; others stress cultural roots, including individuals who do 
not actually speak or understand the heritage language. While 'heritage speakers' are bilingual individuals who speak the heritage language to some degree, 'heritage language learners' are heritage speakers who seek to learn, re-learn, maintain or expand knowledge of their heritage language in the classroom (Kondo-Brown, 2006: 1).

Despite different opinions and perspectives, agreeing to some extent on who a heritage speaker is and what a heritage language learner needs in the classroom is at the heart of heritage language education. Answers to these questions are the first important steps in the creation and implementation of heritage language programs, curricula and assessment aimed at helping language minority students maintain their language and fulfil their linguistic and personal needs.

With respect to linguistic knowledge and patterns of language use, most heritage language speakers and learners, especially those born and schooled in their host country, have perceivable gaps. Typically, a heritage language acquired in childhood may not develop further once schooling in the majority language begins. As a result of incomplete acquisition, many heritage language speakers and learners may exhibit fossilization and/or language attrition in the heritage language. Beyond grammatical competence, many heritage language speakers and learners do not develop the full spectrum of sociolinguistic registers or the level of cognitive and academic literacy commanded by monolingual native speakers (Cummins, 1981; Krashen, 1998; Valdés and Geoffrion-Vinci, 1998). Even when they may speak the language very fluently and with native-like pronunciation, many heritage speakers and learners lack command of late-acquired aspects of language, including forms of address, grammatical and discourse devices, and other aspects of meaning and pragmatics. Aware of their weaknesses, many heritage speakers experience language shyness, tending to avoid interaction with native speakers to minimize embarrassment and feelings of linguistic inadequacy (Krashen, 1998).

Without a doubt, the most severe outcome for heritage language speakers and learners is language loss. The three books place heavy emphasis on the education of heritage language learners whose role is to reverse the trend toward loss, and to salvage heritage languages from their gradual extinction. But more than anything, the three books seek to raise awareness about the importance of heritage languages for the cultural and national health of the nations involved. In their collective 
voices, and in different tones, the three volumes seek to expand the teaching of heritage languages in different academic institutions and to find more precise answers to the complex questions about which programs, teaching methods, and pedagogical materials are best suited for the language maintenance of these learners.

\section{Valdés et al., 2006: Spanish in California}

Developing minority language resources is a case study of Spanish in California. Of all the heritage languages spoken in the USA today, Spanish has the longest history of teaching initiatives for heritage language learners in public schools and universities. Yet despite the size and continued growth of the Spanish-speaking community, Valdés et al. document ongoing language shift to English, which affects not only children but also highly educated Spanish-speaking professionals who need to use Spanish on a daily basis. Valdés et al. contextualize the results of a large-scale research project describing current instructional practices at the secondary and post-secondary levels in the teaching of Spanish to heritage language learners. The book consists of nine chapters, most of them written by Joshua Fishman and Guadalupe Valdés, with Rebecca Chávez and William Pérez collaborating on the chapters describing empirical research. In the first two chapters, Fishman places the root of American language ideology and current policies in their broader historical contexts. In Chapter 1, Fishman examines how the 'failed' history of second/foreign language teaching is closely related to American language ideology, and argues that Spanish and other heritage languages, constitute an untapped resource to promote foreign language competence.

Chapter 2 traces the history of minority language teaching in the USA, including indigenous, colonial and contemporary immigrant heritage languages. While many heritage languages will come and go owing to geopolitical and economic changes, Fishman foresees that Spanish will continue to grow in the USA, and advocates helping Spanish speakers preserve their language across generations.

In Chapter 3, Valdés takes us through time with a vivid and highly informative account of the Spanish presence in California since the time of the Spanish Conquest to the present. Valdés highlights how already in the 19th century Spanish speakers were silenced and 
oppressed by English speakers at the governmental level, and how, to this day, many anti-Spanish policies permeate California's public life. Valdés argues that Americans see Spanish as a threat to the English language and American culture, on the one hand, and as an obstacle to the successful assimilation of Latino immigrants, on the other. According to Valdés, the hostile treatment of the Spanish language and its speakers militates against language maintenance in this population, despite the continuous influx of Spanish speakers.

Chapter 4 presents a survey of 200 educated Latinos from the education, social services, law, medical and government sectors in California, a third of them with advanced degrees. The survey examined beliefs, attitudes and perceived needs about Spanish in California. The results showed that the Latino professionals rarely or only sometimes use Spanish at work, but recommended that Spanish classes focus on cultural connections, content areas and professions.

The next four chapters discuss current practices in foreign language and heritage language teaching of Spanish and present the results of two studies conducted with secondary schools and colleges and universities. In Chapter 5, Valdés surveys the teaching of Spanish in California and underscores the challenges faced by heritage language practitioners who want to develop language resources. Valdés reiterates the position voiced several times elsewhere (Valdés, 1997; 2000): namely, that the varieties of ethnic languages spoken by heritage speakers cannot be compared fairly against the educated monolingual norm; and, second, that proficiency measures developed for foreign language learners do not adequately capture heritage language learners' levels of ability. In Chapters 6 and 7 we learn that a common feature of all the programs for which survey results were available is their emphasis on the standard academic dialect through success in course examinations, reading and writing. Common to all educational institutions surveyed was the instructors' general poor understanding of their students as bilingual individuals. In general, non-Latino instructors described the language proficiency of heritage language students in disapproving terms ('They communicate pretty well orally, not always correctly ... have serious problems with reading and writing'; p. 217), often confusing lack of knowledge of a grammatical meta-language with linguistic limitations ("They should be able to analyze language, and know parts 
of grammar, tenses of verbs. Generally they use them, but cannot identify them'; p. 219). Most disturbing to Valdés et al. is that college instructors regard the educated Spanish of upper class Spanish-speaking monolinguals as the ideal and the primary goal of heritage language instruction. Learning to use the standard language well was assumed 'to lead directly to growth in pride and self-esteem for Latino students' (p.233). In Chapter 8, Valdés engages in severe criticism of the available heritage language teaching practices, claiming they frequently involve ad hoc adaptations of foreign language teaching approaches applied blindly and inappropriately to heritage language learners (p. 235). Valdés advocates a research agenda for heritage language development (p. 242), with the objectives of:

- developing language evaluation assessment procedures that can identify key differences among heritage learners;

- investigating the implicit systems of different types of heritage learners in their non-dominant L1s;

- determining the degree of system restructuring needed for heritage speakers at different levels of proficiency to carry out particular functions in particular settings using appropriate linguistic forms; and

- identifying whether pedagogies used to bring about restructuring of the interlanguages of L2 learners can also be effective.

Fishman closes the book by explicitly encouraging the Spanish-speaking community to become more proactive in political discussions. This population, more than any other in the USA, has the unique opportunity to spearhead the reversal of transgenerational language loss.

In general, Valdés et al. offer a very informative and detailed account of the sociopolitical situation of Spanish in California. Particularly interesting is the rich historical context they provide to help readers grasp the complexity of US language ideology and policy as it relates to current anti-Spanish sentiment in certain segments of the American population. While the specific goals of the research project described are laudable, it is not entirely clear that they have been met. In the end, the results of the two surveys - what Latino professionals think about language maintenance, and what educational institutions actually do to promote maintenance - are not clearly integrated in the conclusion. Throughout the book, current practices for teaching Spanish to heritage speakers at the 
secondary and post-secondary level are denounced for being too traditional in their focus on academic goals (reading and writing).

There are also contradictions. On several occasions throughout the text, Valdés claims that foreign language instruction has little to offer heritage language instruction, but in discussing Silva-Corvalán's (2003) study about incomplete mastery of the Spanish inflectional system, to mention just one example, Valdés writes:

In the case of incomplete acquisition, the instructional problem to be solved might involve, for example, the full acquisition of tense, aspect and mood in the L1. Instructional approaches might therefore include second language methodologies used in the teaching of both oral and written language to L2 learners. (p. 247)

On the next page, however, she writes:

Without evidence to the contrary, one could not conclude that direct forms or formfocused instruction or other typical pedagogies used in L2 instruction would be particularly beneficial in the process of reacquisition or reversal of attrition. (p. 248)

Although many of the observations about the political atmosphere in California are correct, the general rhetoric of protest throughout this volume leaves us with the uneasy feeling that the goals of heritage language education will be hard to meet. At the same time, the book succeeds admirably in raising awareness about the importance and urgency of maintaining Spanish and other heritage languages in the USA.

\section{Kondo-Brown, 2006: East Asian Immigrants in North America}

In Heritage language development, Kimi Kondo-Brown (2006) broadens the perspective presented in Valdés et al. by describing school-age heritage language learners of East Asian descent living in both the USA and Canada. This volume examines how policy-makers, school administrators, teachers and immigrant parents can work together to create optimal learning contexts for the acquisition and maintenance of Chinese, Japanese and Korean at home, in school and in the community. Kondo-Brown also urges more work promoting heritage language development and maintenance in both younger and older learners.

If there is one significantly different aspect between the two books, it is the tone. Valdés et al. reads like a political manifesto, exuding exasperation both with American language ideologies and policies and with many professionals' self-professed ignorance and prejudice toward Spanish heritage language learners. By contrast, Kondo-Brown's 
approach is less confrontational. She starts, for example, by reporting the positive personal consequences of bilingualism for language minority children highlighted in early Canadian research. Like Valdés et al., Kondo-Brown also discusses, but does not overtly condemn, the paradoxical nature of American - and to a lesser extent Canadian - language policies. Kondo-Brown suggests, for instance, that American policies encourage immigrant children to become English speakers at the expense of losing their heritage language, and that many of these learners come to the university to re-learn their family language and complete a foreign language requirement. Although Canadian language policies seem more favourable toward heritage language development than their American counterparts, Kondo-Brown suggests there is still strong opposition to teaching heritage languages in Canadian public schools (Cummins, 1993).

A major salient cultural difference between the Spanish and East Asian populations portrayed in the two books is the active role of East Asian families and communities in the language development and education of their children. Many school-age East Asian heritage language learners study their language in community- and church-based schools for Korean and Chinese and the hoshuukoo or Japanese supplementary schools. These are the main, critical, vehicles for promoting heritage language maintenance in this population during the elementary and high school years. And at the college level, many traditional East Asian language, literature and culture departments also offer courses serving mostly heritage language learners.

All chapters, except for the last one, present original empirical quantitative and qualitative studies describing aspects of heritage language learners' profiles and linguistic abilities. The book is structured into three parts, each consisting of three chapters. Part 1 (Chapters 2-4) focuses on bilingualism in the family and explores factors and practices affecting heritage language development in American and Canadian families. Chapter 2 (Guofang Li) is a case study of two Chinese families residing in Canada. The study reveals the ambivalence that immigrant parents feel: while they strongly support heritage language maintenance, they fear that the heritage language will impede full acquisition of English. Chapter 3 (Mitsuyo Sakamoto) examines similar issues in Japanese families in Toronto using a life history design. 
Chapter 4 (Eunjin Park) highlights the fundamental role that grandparents play in six Korean families, especially in helping children acquire the complex forms of address and grammatical expressions of honorifics. When immigrant children do not interact with older interlocutors, they miss the chance to learn how social hierarchies and politeness rules are encoded in the language. Korean honorifics are a major pedagogical concern in the teaching of Korean as a heritage language.

The next three chapters discuss the role of organized heritage language instruction through educational institutions. Chapter 5 (Kiyomi Chinen and Richard Tucker) present a quantitative study of identity formation in second generation Japanese Americans in 7th-11th grade attending a California-based hoshuukoo, finding that not only does hoshuukoo help these learners develop literacy skills, but it also fosters a positive sense of ethnic group membership. In Chapter 6, Sarah Shin examines the negative effects that current test-driven practices in American elementary schools have on heritage language maintenance. Chapter 7 (Asako Hayashi) examines how different bilingual education programs in the USA and Japan promote heritage language maintenance and biliteracy. Hayashi found that degree of Japanese and English proficiency was related to frequency of language use inside and outside school.

The last three chapters focus on heritage language use and proficiency in school-age heritage language learners. In Chapter 8, Eun Joo Kim reports on a study of factors predicting proficiency in Korean heritage language learners. Accuracy on a Korean proficiency test was positively related to age of immigration, schooling in the language, and proficiency scores. Chapter 9 (Evelyn Yee-fun Man) focuses on strength of language contact and perception of ethnolinguistic vitality in Chinese heritage language children ages 8-18 living in Canada, finding that the children's attitudes, beliefs and perceptions of the Chinese community in Toronto are closely related to extent of use of Chinese. In Chapter 10, Kimi Kondo-Brown summarizes the findings from all these studies and others to suggest directions for further research.

Kondo-Brown (2006) provides an excellent descriptive account of the East Asian immigrant children and their parents. It is very complete in discussing the role of three main agents in successful heritage language 
acquisition: the family, the school and the community. Although the East Asian community faces some of the same challenges and prejudices of the Spanish-speaking community in the USA, Kondo-Brown does not portray East Asian immigrants as victims of the language loss process instigated by language policies and educators. Rather, East Asian families are depicted as the main agents seeking support from school and the community to transmit their language and culture to their children, and thereby retarding intergenerational language loss. And they are quite successful.

\section{Brinton et al., 2008: Some links with second language acquisition}

Heritage language education: a new field emerging includes 20 chapters written by prominent scholars in language policy, linguistics and education, and covers some of the same ground as Valdés et al. and Kondo-Brown: issues related to policy, identity and types of programs, with heavy emphasis on Spanish and East Asian heritage speakers. Nancy Hornberger and Shuhan Wang open the first chapter with questions about precisely defining identity. The rest of the book is organized into three parts. Part I 'Heritage speakers: demographics, policy, and identity,' includes Chapters 2-7; Part II, 'Heritage speaker profiles and needs analysis,' contains Chapters 8-12; and Part III, 'Program development and evaluation,' includes Chapters 13-19. The book closes with Chapter 20, 'Salvaging a childhood language', by Terry Au.

What distinguishes this volume from the other two is its discussion of heritage languages beyond the USA. For example, Joseph Lo Bianco shows how policy initiatives implemented through adult literacy programs contribute to heritage language retention by drawing examples from the linguistic situation in Australia and in Scotland, which has been undergoing revival of Gaelic since 1997. Although the Canadian context is mentioned in Kondo-Brown, Patricia Duff offers in Chapter 4 a more nuanced picture of heritage language education in Canada. Tracing the historical development of language policies favouring heritage languages in Canada, Duff claims that despite Canada's more pluralistic and accepting approach to multiculturalism and heritage languages (compared to US practice), the statistics also 
show a high incidence of heritage language loss among second generation Canadians.

But for those interested in second language acquisition and linguistic issues, Part II is undoubtedly the meat of this book, since it gives a sense of the linguistic repertoire of heritage language learners. Furthermore, some chapters directly compare the linguistic profiles and abilities of L2 learners to heritage speakers. While Spanish and East Asian heritage speakers take the bulk of the volume, the inclusion of two chapters on Russian heritage speakers in this part is particularly welcome.

A pioneer in the study of American Russian and of heritage language systems as linguistic systems in their own right, Maria Polinsky presents in Chapter 8 a small-scale study of two adult heritage speakers and two child heritage speakers, along with two full Russian speakers (child and adult) as controls. The study focuses on the narrative oral production of these speakers and quantifies several grammatical aspects, including number of words, pauses, clauses, embedded clauses, case markers, aspect and tense. Polinsky shows that adult heritage speakers with incomplete knowledge of the language are not just frozen children: their grammatical systems continue to restructure even with impoverished input. In the closing chapter, Terry Au summarizes the results of her research program comparing Spanish and Korean heritage speakers with very low proficiency in those languages to L2 learners of similar low proficiency. She finds that while heritage language learners have advantages over L2 learners in phonology and pronunciation, they do not differ from them in their accuracy of morphosyntax.

On the other side of the proficiency spectrum, in Chapter 11 Claudia Parodi presents both the linguistic characteristics of Chicano Spanish and the profile of advanced heritage language learners who speak that variety. Many of the political and affective issues discussed more broadly in Valdés et al. really come to life in this excellent account of the linguistic repertoire of a Spanish heritage speaker. Furthermore, Parodi provides specific suggestions for how heritage language instruction should differ from L2 instruction. In Chapter 11 Debra Friedman and Olga Kagan describe the academic writing abilities of Russian speakers who moved to the USA between late childhood and adolescence. 
Even though these learners received schooling in Russia, they still have notable gaps in their academic knowledge of Russian. In their smallscale study, Friedman and Kagan compare the production of relative clauses and temporal cohesion devices used in written compositions by educated Russian native speakers, Russian heritage speakers and advanced learners of Russian as a foreign language. Friedman and Kagan found revealing differences between the three groups. The heritage language learners did not use as many relative clauses and temporal cohesion devices as the native speakers, while also showing more lexical knowledge and a variety of syntactic resources not evidenced in the L2 learners' narratives. Similar advantages for heritage language learners over L2 learners in vocabulary, collocations and other aspects of grammatical knowledge are reported by Kanno et al. in their study of advanced learners of Japanese, especially those learners who received supplementary schooling (hoshuukoo) during childhood. All chapters in this section - including Masako Douglas's study of Japanese heritage speakers - show that, in general, heritage language learners have more developed oral than writing skills as suggested by tests that require linguistic manipulation (e.g. cloze, grammaticality judgments, etc.).

While interesting and valuable, the small-scale studies in this section involve very few subjects, and can only be interpreted as preliminary linguistic descriptions. Ideally, the studies discussed by Polinsky, Friedman and Kagan, and Kanno et al. should be expanded into larger scale experimental studies so that their findings can be generalized beyond the individual cases they report, permitting solid implications to be drawn for the classroom.

\section{The relevance of heritage language speakers/learners for second language acquisition}

How are heritage language speakers/learners relevant to the field of L2 acquisition and linguistic theory more generally? In Valdés et al. (2006) and elsewhere (Valdés, 1997; 2005), Valdés repeatedly asserts that efforts at teaching heritage languages are blind ad hoc adaptations of foreign language teaching, and that heritage language research and teaching has so far proceeded without a solid theoretical foundation, implying that no progress in the field can be made without a theory of 
heritage language acquisition (see also Lynch, 2003). Specifically, in Chapter 8 she states:

Second language acquisition theories, as well as traditions now guiding traditional foreign language instruction have little to say about these students and what they should be taught. Existing research on incipient or developing bilingualism in foreign or second languages is of little relevance to teachers of heritage students. Moreover, views about second language (L2) developmental sequences and second language proficiency hierarchies can contribute little to the understanding of the instructional needs of this population. (Valdés et al., 2006: 119)

Even if heritage language learners are in many ways different from typical L2 learners with no previous knowledge of the language, contrary to Valdés, I see many parallels between heritage language and second language acquisition and teaching worth exploring. My understanding of this quote from Valdés is that little is known about the linguistic skills of heritage language speakers, and about how these resemble or do not resemble those of L2 learners. Naturally, without proper understanding of how similar or different these two types of learners are, it is difficult to tell at this point whether the exact same methods applied to L2 learners in the classroom should also be applied to heritage language learners. This, of course, is an open question because other than anecdotal and descriptive accounts of differences, we have no empirical data measuring the effectiveness of L2 methods for heritage language learners.

Where I also disagree with Valdés is on the validity of existing learning theories to unravel heritage language acquisition and development. Heritage speakers are bilingual individuals who share features with L1 acquirers - such as early exposure to the language in a naturalistic setting during a critical period for the development of language - and with adult L2 learners, including restricted access to input, transfer errors and incomplete acquisition, among others. We do not have to reinvent the wheel here: existing theories of L1 and L2 acquisition and bilingualism can be extended to explain and make predictions about the nature of linguistic knowledge of heritage language learners at different ages of development. In fact, I have argued elsewhere (Montrul, 2005; 2006; Montrul et al., 2008) that currently available theories of second language acquisition are very relevant to the investigation and explanation of the nature of linguistic knowledge in these two types of learners. And, seen from another angle, heritage language learners are very 
relevant to second language acquisition and linguistics, since they afford these fields a unique opportunity to evaluate:

- current claims about the complex nature of L1 and L2 competence acquired before and after the so-called critical period;

- the type of knowledge (implicit, explicit) acquired as a result of input and experience;

- the competence-performance dichotomy in formal linguistics;

- the specific innate and environmental ingredients for developing stable native speaker competence;

- the role of transfer and

- the limits and possibilities of bilingual competence in adulthood.

For example, one bone of contention in generative second language research is the explanation for observed differences in the outcome of L1 acquisition and adult L2 acquisition. L2 learners tend to fossilize whereas L1 learners acquire the L1 grammar completely. A likely cause of L2 fossilization is input: L1 learners are exposed to continuous and abundant naturalistic input and have opportunities to use their language. L2 learners, by contrast, receive variable L2 input in type (instructed, naturalistic), amount (more or less frequent) and quality (native vs. non-native), and may not use the L2 as much as L1 learners. The notion that there is a biologically determined propitious time in early childhood during which being exposed to language is crucial for developing linguistic skills has figured prominently in explanations of why adult L2 learners rarely reach the level of linguistic ability of native speakers (see, among others, Bley-Vroman, 1990; Long, 1990; Schachter, 1990; Johnson and Newport, 1991; Meisel, 1997; DeKeyser, 2003; Hyltenstam and Abrahamsson, 2003; Paradis, 2004; Hawkins and Hattori, 2006; Tsimpli and Dimitrakopoulou, 2007). Other researchers downplay the effects of age, maintaining that access to Universal Grammar is not subject to a critical period (Epstein et al., 1996; White and Genesee, 1996). Since heritage language speakers and learners have some characteristics of L1 and some of L2 acquirers, they represent an interesting testing case to tease apart competing positions like these. For example, both L2 learners and heritage speakers exhibit incomplete knowledge of the target language, but they differ with 
respect to experience (use) and age of acquisition. ${ }^{1}$ If age of acquisition is an important factor in bilingual outcomes, as theories of L2 acquisition assume, then it is possible that despite incomplete knowledge later in life, heritage speakers may still possess more native-like knowledge of the target language than L2 learners with similar command of the language, by virtue of the fact that the linguistic or/and cognitive mechanisms assumed to operate for language acquisition in childhood may be different from those deployed in adulthood. Alternatively, if the same learning mechanisms are accessible to the child and adult learner, L2 learners and heritage speakers should not differ.

The studies reported by Au in Brinton et al. (2008) found no advantages for heritage learners on morphosyntax, although morphosyntax was very broadly defined. By contrast, the other chapters in Part II of Brinton et al. as well as my own work on this area suggest that this initial impression may be premature, and that age and exposure also provide an advantage for L2 learners in different aspects of syntax, lexical semantics and inflectional morphology. For example, Montrul (2005) showed that low proficiency heritage speakers made the syntactic distinction between unaccusative and unergative verbs, while L2 learners did not. Montrul (2006) showed how intermediate proficiency heritage speakers had all aspects of the null subject parameter in place whereas the L2 learner counterparts have not yet reset the entire parameter. These studies suggest that aspects of syntax that are acquired very early in childhood are in place and retained by heritage speakers, while L2 learners acquire them more slowly. But when it comes to morphological errors, the picture is less clear. Montrul et al. (2008) showed that both L2 learners and heritage speakers make errors with gender agreement, but heritage speakers make overall fewer errors. Yet, gender errors are manifested differently: heritage speakers made more errors than L2 learners in the written tasks, whereas the L2 learners were less accurate on an oral task, which was assumed to minimize metalinguistic knowledge. Thus, the picture that is emerging thus far is that heritage speakers

\footnotetext{
${ }^{1}$ I agree with an anonymous Second Language Research reviewer that age here is not just biological age but a macro-variable that also subsumes maturational state, cognitive development, degree of L1 proficiency, amount of L1 and L2 use, etc.
} 
appear to have an advantage over L2 learners in some aspects of morphology and syntax as well, not just in phonology.

Related to age is also the issue of language transfer. Recent literature on language acquisition and loss has shown that language transfer occurs both in the L1-to-L2 direction (a typical characteristic of L2 acquisition) and in the L2-to-L1 direction, in the case of L1 loss under intensive contact with an L2 (Cook, 2003). In both cases, the dominant language encroaches into the structure of the less dominant language in systematic ways. The few documented cases of L1 attrition in adults at the level of phonetics (Major, 1992), lexical semantics (Balcom, 2003) and the syntax-discourse interface (Gürel, 2002) can be easily characterized as L2 effects. Heritage speakers are cases of attrition and incomplete acquisition in childhood, the effects of which are more adverse than in adulthood (Montrul, 2008). It is an open question, therefore, as to whether the transfer effects in these two situations are comparable: is L1 influence in adult L2 learners (late bilinguals) similar to L2 influence in early bilinguals? In short, although there is some basic research that systematically compares L2 learners and heritage speakers - as well as research focusing on the systematic nature of incompletely acquired L1 grammatical systems in children and adults (Silva-Corvalán, 1994; 2003; Håkansson, 1995; Song et al., 1997; Anderson, 1999; Montrul, 2002; 2004; Kondo-Brown, 2005; Polinsky, 2006; 2008; Bolonyai, 2007) - this trend should continue. The findings from these research programs have much bearing on our understanding of the role of age on language acquisition and loss more generally, and they are crucial to inform linguistic theory and the heritage language teaching profession.

In conclusion, the study of heritage language learners has boomed in the last few years, as vividly illustrated in these three new books. Despite obvious differences between L2 learners and heritage speakers, there are important language learning issues that affect the two populations. Linguistic approaches to L2 acquisition have often been criticized for not having pedagogical implications. I believe that linguistic theory applied to L2 acquisition and adult early bilinguals remains a crucial tool for generating research questions and for guiding the design of linguistically-informed instruments to identify systematic and measurable differences and similarities between these two types of language learners. 
Once we acquire a better sense of the linguistic knowledge heritage language and L2 learners have or lack - and this is communicated to the teaching profession - practitioners will be in a much better position to advocate for separate programs for heritage language learners, or to address both learners' linguistic and pedagogical needs, especially when they find themselves sharing the same L2 class.

\section{Acknowledgements}

I am grateful to Margaret Thomas for giving me the opportunity to write this review and for her insightful editorial suggestions. I also thank an anonymous Second Language Research reviewer for feedback and suggestions.

\section{References}

Anderson, R. 1999: Noun phrase gender agreement in language attrition, Preliminary results. Bilingual Research Journal 23, 318-37.

Balcom, P. 2003: Crosslinguistic influence of L2 English on middle constructions in L1 French. In Cook, V., Effects of the second language on the first. Clarendon: Multilingual Matters, 168-92.

Bley-Vroman, R. 1990: The logical problem of foreign language learning. Linguistic Analysis 20, 3-49.

Bolonyai, A. 2007: (In)vulnerable agreement in incomplete bilingual L1 learners. The International Journal of Bilingualism 11, 3-21.

Cook, V., editor, 2003: The effects of the second language on the first. Clevedon: Multilingual Matters.

Cummins, J. 1981: Four misconceptions about language proficiency in bilingual education. NABE Journal, 5 (3), 31-45.

— 1993: The research basis for heritage language promotion. In Danesi, M., McLeod, K. and Morris, S., editors, Heritage language and education: the Canadian experience. Ontario: Mosaic Press, 1-21.

DeKeyser, R. 2003: Implicit and explicit learning. In Doughty, C. and Long, M., editors, The handbook of second language acquisition. Malden, MA: Blackwell, 313-48.

Epstein, S., Flynn, S. and Martohardjono, G. 1996: Second language acquisition, theoretical and experimental issues in contemporary research. Behavioral and Brain Sciences 19, 677-758.

Gürel, A. 2002: Linguistic characteristics of second language acquisition and first language attrition: Turkish overt vs. null pronouns. Unpublished doctoral dissertation, McGill University, Montreal. 
Hawkins, R. and Hattori, H. 2006: Interpretation of English multiple whquestions by Japanese speakers: a missing uninterpretable feature account. Second Language Research 22, 269-301.

Håkansson, G. 1995: Syntax and morphology in language attrition: a study of five bilingual expatriate Swedes. International Journal of Applied Linguistics 5, 153-71.

Hyltenstam, K. and Abrahamsson, N. 2003: Maturational constraints in SLA. In Doughty, C. and Long, M., editors, The handbook of second language acquisition. Oxford: Blackwell, 539-88.

Johnson, J. and Newport, E. 1991: Critical period effects on universal principles of language: the status of subjacency on the acquisition of a second language. Cognition 39, 215-58.

Kondo-Brown, K. 2005: Differences in language skills: heritage language learner subgroups and foreign language learners. Modern Language Journal 89, 563-81.

Krashen, S. 1998: Language shyness and heritage language development. In Krashen, S.D., Tse, L. and McQuillan, J., editors, Heritage language development. Culver City, CA: Language Education Associates, 41-49.

Long, M. 1990: Maturational constraints on language development. Studies in Second Language Acquisition 12, 251-85.

Major, R.C. 1992: Losing English as a first language. The Modern Language Journal 76, 190-209.

Meisel, J. 1997: The acquisition of the syntax of negation in French and German: contrasting first and second language development. Second Language Research 13, 227-63.

Montrul, S. 2002: Incomplete acquisition and attrition of Spanish tense/aspect distinctions in adult bilinguals. Bilingualism: Language and Cognition 5, 39-68.

_ 2004: Subject and object expression in Spanish heritage speakers: a case of morpho-syntactic convergence. Bilingualism: Language and Cognition 7, 125-42.

2005: Second language acquisition and first language loss in adult early bilinguals: exploring some differences and similarities. Second Language Research 21, 199-249.

- 2006: Incomplete acquisition as a feature of L2 and bilingual grammars. In Slabakova, R., Montrul, S. and Prévost, P., editors, Inquiries in language development: studies in honor of Lydia White. Amsterdam: John Benjamins, 335-59.

2008: Incomplete acquisition in bilingualism: re-examining the age factor. Series on Studies in Bilingualism. Amsterdam: John Benjamins.

Montrul, S., Foote, R. and Perpiñán, S. 2008: Gender agreement in adult second language learners and Spanish heritage speakers: the effects of age and context of acquisition. Language Learning 58, 503-53. 
Paradis, M. 2004: A neurolinguistic theory of bilingualism. Amsterdam: John Benjamins.

Polinsky, M. 2006: Incomplete acquisition: American Russian. Journal of Slavic Linguistics 14, 191-262.

— 2008: Russian gender under incomplete acquisition. The Heritage Language Journal 6 (1). Spring 2008. See http://www.heritagelanguages.org (July 2008)

Schachter, J. 1990: On the issue of completeness in second language acquisition. Second Language Research 6, 93-124.

Silva-Corvalán, C. 1994: Language contact and change: Spanish in Los Angeles. Oxford: Oxford University Press.

- 2003: Linguistic consequences of reduced input in bilingual first language acquisition. In Montrul, S. and Ordóñez, F., editors, Linguistic theory and language development in Hispanic languages. Somerville, MA: Cascadilla Press, 375-97.

Song, M., O'Grady, W., Cho, S. and Lee, M. 1997: The learning and teaching of Korean in community schools. In Kim, Y.-H., editor, Korean language in America, volume 2. American Association of Teachers of Korean, 111-27.

Tsimpli, I. and Dimitrakopoulou, M. 2007: The interpretability hypothesis: evidence from $w h$-interrogatives in second language acquisition. Second Language Research 23, 215-42.

Valdés, G. 1997: The teaching of Spanish to bilingual Spanish-speaking students: outstanding issues and unanswered questions. In Colombi, M.C. and Alarcón, F., editors, La enseñanza del español a hispanoahablantes. Boston, MA: Houghton Mifflin, 8-44.

— 2000: Introduction. Spanish for native speakers, volume I. AATSP Professional Development Series Handbook for teachers K-16. New York: Harcourt College.

— 2005: Bilingualism, heritage language learners, and SLA research: opportunities lost or seized? Modern Language Journal 89, 410-26.

Valdés, G. and Geoffrion-Vinci, M. 1998: Chicano Spanish: the problem of the 'underdeveloped' code in bilingual repertoires. Modern Language Journal 82, 473-501.

White, L. and Genesee, F. 1996: How native is near-native? The issue of ultimate attainment in adult second language acquisition. Second Language Research 12, 238-65. 